This is the peer reviewed version of the following article: Marital relationship and health-related quality of life after prostate cancer diagnosis. Harju Eeva, Rantanen Anja, Kaunonen Marja, Helminen Mika, Isotalo Taina, Åstedt-Kurki Päivi. International Journal of Urological Nursing. 2017. Vol. 11, no. 2, pp. 73-81, which has been published in final form at http://dx.doi.org/10.1111/ijun.12131. This article may be used for non-commercial purposes in accordance with Wiley Terms and Conditions for Self-Archiving.

\title{
Marital relationship and health-related quality of life after prostate cancer diagnosis
}

\author{
Eeva HARJU, MNSc, RN
}

(correspondence)

Doctoral Candidate

School of Health Sciences, Nursing Science, University of Tampere

Arvo, FI-33014 University of Tampere, Finland

eeva.j.harju@uta.fi

Anja RANTANEN, PhD, RN

Docent, University Teacher

School of Health Sciences, Nursing Science, University of Tampere

Arvo, FI-33014 University of Tampere, Finland

anja.rantanen@uta.fi

Marja KAUNONEN, PhD, RN

Professor

School of Health Sciences, Nursing Science, University of Tampere

Arvo, FI-33014 University of Tampere, Finland

Department of General Administration, Pirkanmaa Hospital District

PO Box 2000, FI-33521 Tampere University Hospital, Finland

marja.kaunonen@uta.fi 
Mika HELMINEN, MSc

Biostatistician

School of Health Sciences, University of Tampere

Arvo, FI-33014 University of Tampere, Finland

Science Centre, Pirkanmaa Hospital District

PO Box 2000, FI-33521 Tampere University Hospital, Finland

mika.helminen@uta.fi

Taina ISOTALO, M.D., PhD

Chief Urologist

Department of Surgery, Päijät-Häme Central Hospital

Keskussairaalankatu 7, FI-15850 Lahti, Finland

taina.isotalo@phsotey.fi

Päivi ÅSTEDT-KURKI, PhD, RN

Professor

School of Health Sciences, Nursing Science, University of Tampere Arvo, FI-33014 University of Tampere, Finland

Department of General Administration, Pirkanmaa Hospital District PO Box 2000, FI-33521 Tampere University Hospital, Finland paivi.astedt-kurki@uta.fi 


\section{Abstract}

Prostate cancer has an impact on the health-related quality of life of patients and their spouses. However, the marital relationship at the time of prostate cancer diagnosis is not well known. The aim of the study was to describe and compare the marital relationship of patients with prostate cancer and their spouses and to identify factors associated with health-related quality of life at the time of diagnosis. The data of this cross-sectional study were collected with The Marital Questionnaire and RAND-36 Item Health Survey scales after the diagnosis of prostate cancer from 232 patients and 229 spouses at five Finnish central hospitals from October 2013 - January 2016. Patients with prostate cancer rated their dyadic satisfaction better than their spouses. Respectively, spouses reported better dyadic cohesion. The marital relationship of the patients or spouses was not associated with demographic variables of the respondents. In patients, energy, emotional well-being and general health were associated with the marital relationship. In spouses, emotional role functioning, emotional well-being and social functioning were explained by the marital relationship. At the time of diagnosis, the marital relationship of patients with prostate cancer and their spouses was good. However, there were differences in associations between patients' and their spouses' marital relationship and health-related quality of life. Based on the results of this study, it is useful to take into account the spouses and the marital relationship in the nursing of patients with prostate cancer. The follow-up research on this subject is needed.

Key words: Health-related quality of life, Marital relationship, Marital questionnaire, Patient with prostate cancer, RAND-36, Spouse 


\section{Background for the study}

Prostate cancer is the most common malignancy among males in Western Europe and in Finland (Ferlay et al., 2015; Engholm et al., 2015). In Finland, over one-third of all new cancers every year are prostate cancer, which means more than 4,700 Finnish men are diagnosed with prostate cancer each year (Engholm et al., 2015). Average age of patients with prostate cancer is 70 years, and $80 \%$ live in a marital relationship (Lehto et al., 2015). All treatment methods for prostate cancer are related to the distinct pattern of changes in quality of life (Sanda et al., 2008); moreover, spouses play a central role in men's choice of treatment (Maliski et al., 2002). It is, therefore, essential to describe the perceived marital relationship of patients with prostate cancer and their spouses and its connection to health-related quality of life (HRQoL) at the time of diagnosis.

Within the context of public health, HRQoL is documented as an important health outcome, in addition to morbidity and mortality (Horner-Johnson et al., 2009). HRQoL has been described as an overall experience of physical, functional, psychological and social wellbeing (Zhan, 1992; Aalto et al., 1999). Cancer in one family member has a significant impact on the whole family. Caring for a family member with cancer can be demanding and increase the responsibilities of others during and after the patient is undergoing cancer treatment and rehabilitation (Stenberg et al., 2010; Ervik et al., 2013). A Finnish study indicated that patients with cancer and their spouses who were optimistic and had a strong sense of coherence reported fewer symptoms of distress (Gustavsson-Lilius, 2010). There is even evidence for the fact that a cancer diagnosis affects spouses emotionally more than the patients, which is manifested in the spouses' depression and distress symptoms (GustavssonLilius, 2010; Regan et al., 2014). Supportive dyadic coping by each spouse alone and together 
was significantly associated with greater patient and spouse relationship satisfaction (Regan et al., 2014).

Spouses are affected by prostate cancer, as has been reported in previous studies (Maliski et al., 2002; Harden et al., 2006; Ervik et al., 2013). The spouse affects the patient's quality of life, and the patient affects the spouse's quality of life (Kershaw et al., 2008). Spouses reported greater psychological distress than the patients themselves at the time of diagnosis and after the treatment (Harden, 2005, Galbraith et al., 2008; Galbraith et al., 2011; Ervik et al., 2013). Spouses assumed an active role in their husbands' prostate cancer; they were the ones who encouraged their husbands to seek treatment, were their husbands' primary source of support and frequently were the communication conduit between their husbands and their physicians and nurses (Gray et al., 2000; Harden et al., 2002).

The adverse effects of prostate cancer treatment, such as incontinence and erectile dysfunction, contribute to marital distress in spouses. Talking about cancer and sexual dysfunction has been shown to be a source of distress for both the patients and their spouses (Harden et al., 2002; Northouse et al., 2007; Badr and Taylor, 2009; Ervik et al., 2013). Spouses strived to achieve a balance between focusing on their own needs and meeting their husbands' needs throughout the course of the illness (Ervik et al., 2013). For some couples, the cancer experience could ultimately result in a closer relationship. Half of the spouses reported that the experience of the diagnosis and deciding on the treatment brought them and their husbands closer together and strengthened their relationship (Harden et al., 2002; Resendes and McCorkle, 2006). On the other hand, patients with prostate cancer do not accept that spouses fight the disease instead of them; they believe that their spouses invest in 
the fight because they cannot or they are not strong enough to do that themselves (Lafaye et al., 2014).

Spouses' negative appraisal of their caregiving experience had a reciprocal effect on quality of life so that more negative appraisals resulted in more marital distress, less satisfaction with the sexual relationship and lower quality of life scores (Harden et al., 2013b). According to Merz et al. (2011), dyadic disagreement is associated with worse HRQoL in couples facing prostate cancer. Prostate cancer threatens marital quality, which can in turn reduce each spouse's quality of life; hence, the marital relationship can be complicated by illness (Winters-Stone et al., 2012).

Changes in a long-standing relationship, role reversal and decreased social interactions required adaptation. Although spouses were strongly committed to assisting their husbands through their experience, they were simultaneously adjusting to significant changes in their own lives as well (Maliski et al., 2002, Harden et al., 2006). Younger spouses particularly who had negative appraisals of their caregiving experience had lower marital and sexual satisfaction and poorer quality of life (Harden et al., 2013b). According to recommendations (Harden et al., 2006, Harden et al., 2013b), interventions designed for patients with prostate cancer should also focus on spouses and family members. This increases the effect of the intervention, enabling the spouse and family to support the patients with prostate cancer as the recovery proceeds. (Ching-Hui et al., 2014). Often, couples would like even more information related to the strategies that focus on improving their quality of life and intimacy (Galbraith et al., 2011). 


\section{Research questions}

The purpose of the study was to describe the marital relationship and HRQoL in patients with prostate cancer and their spouses after prostate cancer diagnosis.

The research questions were:

1. What is the marital satisfaction of patients with prostate cancer and spouses at the time of their confirmed diagnosis?

2. How are demographic variables associated with marital satisfaction in patients with prostate cancer and spouses?

3. How is marital satisfaction associated with HRQoL in patients with prostate cancer and spouses?

\section{Sample}

The sample consisted of patients with prostate cancer and their spouses from the urology clinics of five Finnish central hospitals. Collectively, the population in the area of these hospitals is about 1 million persons. Before the start of recruitment, the sample size was calculated together with a statistician. Ten points can be a clinically significant change when the quality of life is measured (Osoba et al., 2005). The sample size calculation was based on a paired-samples t-test. Using a standard deviation of 20, with the alpha value set at 0.05 and the power at 0.8 , a change of 10 points was calculated to be statistically significant with a sample of 33 respondents (Osoba et al., 2005). To attention taking non-responses in three different measuring points, at least four types of treatment and five different hospitals the questionnaire was distributed to 350 patients and their spouses $(\mathrm{N}=350)$. Responses were received from 232 patients and 229 spouses; the patients' response rate was $66 \%$, and the spouses' $65 \%$. The original power calculation is performed as described above. In practice, it 
was found that the changes were smaller than expected, so the original plan of analyzing hospitals separately was rejected.

The inclusion criteria were as follows: (1) The patient was diagnosed with prostate cancer and was at the pre-treatment stage, (2) The patient characterised the relationship to his spouse as permanent and (3) He provided written informed consent with the additional contact information for his spouse. The treatment method regarding prostate cancer did not influence inclusion in the study.

\section{Data collection methods}

The research was undertaken between October 2013 and January 2016. The recruited patient received questionnaire forms for both himself and his spouse, with a return envelope, during his appointment with a nurse. The filled-in questionnaires were mailed in separate envelopes with prepaid postage to the researcher's office. The questionnaire consisted of the Finnish version of the RAND 36-Item Health Survey (RAND-36) (Aalto et al., 1999) and The Marital Questionnaire (Saarijärvi 1991) and background variables. The instruments were selected because they were suitable for both patients with prostate cancer and their spouses and they had been used in Finland, for example Vasarainen et al. (2013) and Ylilehto (2005) and internationally for example Cary et al. (2014) and Jenewein et al. (2008).

\section{RAND-36-Item Health Survey}

HRQoL was measured with RAND-36, which contains the same questions as the MOS SF-36 (Ware \& Sherbourne 1992, Hays et al. 1993, Aalto et al., 1999). RAND-36 is a generic health-related survey consisting of 36 items with eight subscales: physical functioning, role functioning/physical, role functioning/emotional, energy, emotional well-being, social 
functioning, bodily pain and general health perceptions. All eight subscales are separately scored from 0 to 100, where a higher score indicates a better HRQoL. The items were scored on two six-point Likert-type scales. RAND-36 is an instrument used internationally in measuring the HRQoL of patients with prostate cancer (Treiyer et al., 2011, Dieperink et al., 2012, Cary et al., 2014) and their spouses (Harden et al., 2013a). The Finnish version of RAND-36 has been validated and has good reproducibility in the Finnish population (Cronbach's alpha 0.80-0.94) (Aalto et al., 1999). In our study groups, Cronbach's alpha coefficients for the RAND-36 scale ranged from 0.85 to 0.87 in the patient sample and from 0.82 to 0.84 in the spouse data, demonstrating good internal consistency (Burns and Grove, 2009).

\section{The Marital Questionnaire}

The Marital Questionnaire was used to measure the patients' and spouses' perspectives of their marital relationship. The items on the questionnaire were combined from two validated and internationally used instruments for measuring marital satisfaction. Fourteen of the items are from the Dyadic Adjustment Scale (DAS) (Spanier, 1976) which is a widely used measure with modified versions (Graham et al., 2006). The DAS has been used in researching the impact of cancer on relationships (Jenewein et al., 2008). The additional 6 items on the questionnaire are from the Marital Communication Inventory (Bienvenu, 1970). The reliability of Marital Communication Inventory has been shown to be high (Cronbach's $\alpha=0,93$ ) (Bienvenu, 1970).

In the questionnaire, a marital relationship consists of the subscales of dyadic consensus (9 items), dyadic cohesion (3 items), dyadic satisfaction (2 items) and communication (6 items). The items were scored on a five-point Likert-type scale $(1=$ definitely agree/often $-5=$ 
definitely disagree/seldom) All items on the marital relationship scale were combined to create a summated scale. (Table 2). The Marital Questionnaire was compiled and translated into Finnish by Saarijärvi (1991). He has used the questionnaire for measuring the impact of family-oriented rehabilitation on chronic low back pain patients. The Marital Questionnaire has also been used in describing the marital relationship of women during childbirth (Ylilehto, 2005). The inter-item correlations varied between 0.63-0.81 (Saarijärvi 1990). In this study, Cronbach's alpha coefficients for the marital relationship scale ranged from 0.52 to 0.87 in the patient sample and from 0.49 to 0.89 in the spouse data.

Patient demographic characteristics included age, duration of marital relationship, basic and vocational education, employment status, other disorders, the hospital where the cancer was treated and treatment methods for prostate cancer. Among the spouse's demographic variables were age, duration of marital relationship, basic and vocational education, employment status and long-term disorders.

\section{Ethical considerations}

The Scientific Committee of the local hospital district reviewed the ethicality of this study, and the directors of the five participating hospitals permitted its execution. The respondents were written and orally informed of the purpose of the study and of the principle of voluntary, anonymous participation.

\section{Data analysis}

Variables were described as frequency and percentage distributions as well as location and standard deviation parameters. Firstly, the quality of life subscales of RAND-36 were recoded according to the scoring instructions of the instrument (Aalto et al. 1999). After this, 
summated variables of the eight subscales were formed from the indices. The resulting subscale scores are on a 0-100 scale, with higher values representing a more favourable health-related quality of life. (Aalto et al., 1999). Respectively, the items in the marital questionnaire were scored and analysed according to instructions of the instrument (Ylilehto 2005). Higher value indicated greater quality of marital relationship.

As the dimensions of HRQoL and marital relationship did not meet the assumption of normality, we used the Wilcoxon Signed Ranks, Mann-Whitney and Kruskal-Wallis tests to examine associations. The cut-off of the good and poor HRQoL was the mean of the agestratified general male/female population added to half of the standard deviation (Pekkonen, 2010). Logistic regression models with the enter method were used to assess the marital relationship of patients and their spouses for all eight dimensions of the HRQoL. All eight RAND-36 dimensions were divided into two scores (higher values $=1$, lower values $=0$ ) based on the age-stratified general male/female population (Aalto et al., 1999). All the background variables and the dimensions of marital relationships were entered in the logistic regression model using the enter method. Results were reported by Cox \& Snell $\mathrm{R}^{2}$ and p-value. The level of statistical significance was set at $\mathrm{P}<0.05$. The IBM SPSS statistics Version 23 (IBM Corp., Armonk, NY, USA) was used to analyse the data (Munro, 2005).

\section{Results}

\section{Demographic characteristics of respondents}

The demographic characteristics of the patients with prostate cancer and spouses are presented in Table 1. The mean age of the patient with prostate cancer sample was 68 years ( $\mathrm{SD}=8.4$, range $40-86)$. The mean age of the spouse sample was 65 years $(\mathrm{SD}=9.0$, range $33-$ 85). The average duration of marital relationship was 36 years $(\mathrm{SD}=16.0$, range $1-60)$. More 
than two-thirds of the patients with prostate cancer and less than half of the spouses had completed either elementary school or civic school. More than half of the respondents were not working, most of them were retired. Over two-thirds of the patients and spouses had a chronic disease. The planned treatment method for prostate cancer for over one-third of the patients was non-invasive care.

\section{The marital relationship according to four dimensions}

The marital relationship and its dimensions are presented in Table 2. Both the patients with prostate cancer (mean=4.0, $\mathrm{SD}=0.4)$ and their spouses (mean=4.0, $\mathrm{SD}=0.5$ ) rated their marital relationship 'good'. The patients' and the spouses' ratings of their dyadic consensus were very similar. Nearly all patients and spouses reported that they agree on the handling of family finances and on matters of recreation. Similarly, the respondents experienced mutual agreement on concepts believed important and their philosophy of life. Two in three of the patients and spouses felt that they agree on sexual relations. More than two in three of the patients and spouses reported that they agree on ways of dealing with relatives or in-laws and friends.

The patients and the spouses gave similar scores for dyadic cohesion. Even so, the spouses reported not much higher levels of dyadic cohesion. The difference was statistically significant $(\mathrm{p}=0.034)$. Four out of five patients and spouses reported that they often discuss some things calmly. More than two in three of patients and spouses often worked together on a project and had a stimulating exchange of ideas. The patients with prostate cancer reported higher levels of dyadic satisfaction than the spouses. The difference between the means was statistically significant $(\mathrm{p}=0.001)$. Less than one percent of the patients and three percent of 
the spouses had often considered divorce. Less than five percent of the respondents reported that they often quarrel with their spouse.

The spouses gave higher scores for communication than the patients, but the difference was not significant. Less than one in five of the respondents failed to express disagreement with their spouse because of fear that their spouse would get angry. Over two in three of the patients and spouses experienced expressing their true feelings to their spouse as not difficult. Likewise, two in three of the respondents seldom hesitated to discuss certain things with their spouse because of fear of their feeling getting hurt. Only seven percent of the patients and five percent of the spouses felt that their spouse complained about a lack of understanding. One in five of the patients and spouses often engaged in outside interests and activities together. Two in three of the patients and spouses seldom pretended to listen to their spouse when they were not really listening.

Demographic characteristics and marital relationships in patients with prostate cancer and their spouses

There was no evidence of an association between marital relationships and demographic variables of patients with prostate cancer and their spouses; hence, data were not shown in a table.

\section{Health-related of quality of life}

The participants' HRQoL was good before the start of prostate cancer treatment. Social and physical functioning were the best dimensions of HRQoL for both the patients and their spouses. Correspondingly, the general health was the participants' weakest dimension. There 
was no statistically significant association between the means of patients and spouses; consequently, descriptive data regarding HRQoL were not shown in the table.

Association between the marital relationship of the patients with prostate cancer and their $H R Q o L$

Logistic regression analysis was used to explore the background variables of age, duration of marital relationship, basic education, vocational qualifications, employment status, other diseases and treatment method for prostate cancer regarding HRQoL. The background variables showed significant associations with physical functioning, energy, social functioning and general health (Table 3). When the marital relationship was added to the model, it explained energy, emotional well-being and general health of patients with prostate cancer.

Association between the marital relationship of the spouses and their HRQoL

The spouses' age, the duration of the marital relationship, basic education, vocational qualifications, employment status and other diseases explained physical functioning, physical and emotional role functioning, bodily pain and general health. (Table 3.) When model was appended with marital relationship, it additionally explained the spouses' emotional role functioning, emotional well-being and social functioning statistically significantly.

\section{Conclusions, implications for practice}

The main interest of this study was to describe and compare the marital satisfaction of patients with prostate cancer and their spouses and to identify marital relationship was associated with HRQoL at the time of diagnosis. Both patients and spouses rated their marital relationship 'good'. These findings are in agreement with previous studies (Banthia et al., 
2003; Couper et al., 2006; Galbraith et al., 2008), which concluded that both members of the dyad report similar perceptions when asked about their marital relationship. When each member of a dyad is asked about his/her own specific health issue, their reports are not explicitly linked (Maliski et al., 2002; Banthia et al., 2003).

The possible differences between the patients and their spouses in their experience of the marital relationship could arise later. For example, spouses are more distressed at the time of diagnosis and less so six months later; the opposite occurred in the patients (Couper et al., 2006). Patients' marital satisfaction levels remained constant over six months, but spouses' satisfaction declined (Couper et al., 2006). It could also be possible that the spouses do not discuss their experiences quite truthfully because their husbands only recently became ill with the prostate cancer. According to Paterson et al. (2015), spouses had to suppress and conceal their own emotional needs to protect their husbands'. Some spouses also spoke about the innate instinct to provide for the family following treatment (Paterson et al., 2015). In addition, studies have shown patients with prostate cancer believed that their cancer and subsequent alterations to their sexual function had not impacted on their masculinity, though spouses felt that their men's masculinity had been challenged (O'Shaughnessy et al., 2013). Patients with prostate cancer who reported high levels of mutual constructive communication also reported better marital adjustment than those who reported low levels of mutual constructive communication, regardless of their level of erectile dysfunction (Badr and Taylor, 2009). Spouses experienced negative appraisals that affected sexual satisfaction and quality of life three years following the patient's treatment for prostate cancer (Harden et al., 2013a). 
According to this study, there was no evidence of an association between the marital relationship and demographic characteristics of patients with prostate cancer or spouses. The potential associations in marital relationship of patients with prostate cancer and their spouses possibly come up during and after prostate cancer treatment. On the other hand, participants of this study have longstanding marital relationships; the average duration of marital relationship was 36 years.

The results of the present study showed that marital relationships were associated with patients' energy, emotional well-being and general health. Among spouses, emotional role functioning, emotional well-being and social functioning were associated with the marital relationship. Earlier studies have found that being in a relationship is a supportive factor among patients with prostate cancer (Banthia et al., 2003; Fagundes et al., 2012; O'Shaughnessy et al., 2015). In all probability, the patients' and their spouses' age and chronic diseases have contributed to their HRQoL. According to results of these studies, the marital relationship is connected to the patients' and their spouses' HRQoL. At any rate, patients and their spouses experienced the effect of the marital relationship on the HRQoL in a slightly different way. One possibility is that spouses focus more of their attention on their relationship and value open spousal communication more than patients, as reported by a previous study (Badr and Taylor, 2009). In this study, the marital relationship increased both patients' and spouses' emotional well-being. It means the mood and feeling of happiness or unhappiness. The marital relationship explained higher energy and general health of patients with prostate cancer. Correspondingly, the marital relationship explained spouses' better coping with work or daily tasks, even if spouses had depression or anxiety. Furthermore, the marital relationship explained the spouses' social functioning, which pertains to the usual social activity among a family, friends, neighbors and other people. 
The study has several limitations. The demographic variables of the questionnaire were modified for use with patients with prostate cancer and their spouses. The HRQoL was measured using a generic HRQoL instrument that has been extensively validated and used earlier. Likewise, a marital questionnaire was composed of two generic and internationally used scales. Internal consistency as measured by Cronbach's alpha was good for the both scales. Regardless of the prospective treatment of prostate cancer, the patients with prostate cancer and their spouses were included in the study, which means that the results can be extrapolated to all Finnish patient with prostate cancer, who have a permanent marital relationship.

On the other hand, the sample was fairly small, although according to the power analysis the sample was adequate. The length of the questionnaire, research topic and moment; they have been allowed recently to hear about the prostate cancer diagnosis could have affected the response rate. Self-reported data on early diseases and prostate cancer treatment are limited by patients' understanding and recall of treatments. Even though participants were guided to fill in the questionnaires separately, it is still likely that some couples discussed the items together. It is possible that, in the sample of the study, selecting has taken place. The patients and their spouses who accepted involvement in the survey could have better health, and perhaps their marital relationship is stable. This bias could lead to the fact that the quality of life and marital relationship appear better in the results than in reality.

This study showed that, at the time of diagnosis, the marital relationship of patients with prostate cancer and their spouses was good. The patients reported higher levels of dyadic satisfaction than spouses. The demographic variables of patients with prostate cancer and 
their spouses were not associated with the marital relationship. There were differences in associations between patients' and their spouses' marital relationship and their HRQoL.

\section{Clinical Implications}

In summary, we suggest that nurses and other health professionals take into account the spouses working with patients with prostate cancer, for examples, by giving the spouses the opportunity to discussion. The marital relationship explained in different ways the patients with prostate cancer and their spouses of the HRQoL at the time of diagnosis. Therefore, we could recommend that counselling and support to the patient and their spouses should be individually modified. Furthermore, there is a need for follow-up research to assess long-term changes in marital relationship and its association with HRQoL of patients with prostate cancer and their spouses.

\section{WHAT IS KNOWN ABOUT THIS TOPIC}

It is know that prostate cancer influences on the HRQoL of patients with prostate cancer and their spouses. This paper contributes to understand how the marital relationship is associates with HRQoL of patients and their spouses.

\section{WHAT THIS PAPER ADDS}

A marital relationship affects the HRQoL of life of both patients with prostate cancer and their spouses. Furthermore, the marital relationship is associated with emotional well-being of both patients with prostate cancer and their spouses at the time of diagnosis. 


\section{References}

Aalto A, Aro AR, Teperi, J. (1999). RAND-36 as a measure of Health-Related Quality of

Life. Reliabilty, construct validy and reference values in the Finnish general population.

Stakes, Research Reports 101, Helsinki.

Badr H, Taylor CLC. (2009). Sexual dysfunction and spousal communication in couples coping with prostate cancer. Psycho-Oncology; 18: 735-746.

Banthia R, Malcarne VL, Varni JW, Ko CM, Sadler GR, Greenbergs HL. (2003). The effects of dyadic strength and coping styles on psychological distress in couples faced with prostate cancer. Journal of Behavioral Medicine; 26: 31-52.

Bienvenu Sr MJ. (1970). Measurement of Marital Communication. The Family Coordinator; 19: $26-31$.

Burns N, Grove SK. (2009). The Practice of Nursing Research: Appraisal, Synthesis, and Generation of Evidence, sixth edition. St. Louis, MO: Saunders Elsevier.

Cary K, Singla N, Cowan J, Carroll P, Cooperberg M. (2014). Impact of androgen deprivation therapy on mental and emotional well-being in men with prostate cancer: analysis from the CaPSURETM registry. Journal of Urology; 191: 964-970.

Ching-Hui C, Kuan-Lin L, Hui-Tsu C, Hsueh-Erh L. (2014). The effects of psychosocial strategies on anxiety and depression of patients diagnosed with prostate cancer: A systematic review. International Journal of Nursing Studies; 51: 28-38. 
Couper JW, Bloch S, Love A, Duchesne G, Macvean M, Kissane DW. (2006). The psychosocial impact of prostate cancer on patients and their partners. The Medical Journal of Australia; 185: 428-432.

Dieperink KB, Hansen S, Wagner L, Johansen C, Andersen KK, Hansen O. (2012). Living alone, obesity and smoking: Important factors for quality of life after radiotherapy and androgen deprivation therapy for prostate cancer. Acta Oncologica; 51: 722-729.

Engholm G, Ferlay J, Christensen N, Kejs AMT, Hertzum-Larsen R, Johannesen TB, Khan S, Leinonen MK, Olafsdottir E, Petersen T, Schmidt LKH, Trykker H, Storm HH. NORDCAN. (2015). Cancer incidence, mortality, prevalence and survival in the Nordic countries, Version 7.2. Association of Nordic Cancer Registries. Copenhagen: Danish Cancer Society. http://www.ancr.nu/ancr/ (accessed 05/02/16).

Ervik B, Nordoy T, Asplund K. (2013). In the middle and on the sideline: The experience of spouses of men with prostate cancer. Cancer Nursing; 36: E7E-14.

Fagundes CP, Berg CA, Wiebe DJ. (2012). Intrusion, avoidance, and daily negative affect among couples coping with prostate cancer: A dyadic investigation. Journal of Family Psychology; 26: 246-253.

Ferlay J, Soerjomataram I, Ervik M, Dikshit R, Eser S, Mathers C, Rebelo M, Parkin D, Forman D, Bray F. 2015. GLOBOCAN 2012 v1.0, Cancer Incidence and Mortality Worldwide: IARC CancerBase No. 11 Lyon, France: International Agency for Research on Cancer; 2013, http://globocan.iarc.fr Accessed 31 August 2015). 
Galbraith ME, Pedro LW, Jaffe AR, Allen TL. (2008). Describing health-related outcomes for couples experiencing prostate cancer: Differences and similarities. Oncology Nursing Forum; 35: 794-801.

Galbraith ME, Fink R, Wilkins GG. (2011). Couples surviving prostate cancer: Challenges in their lives and relationships. Seminars in Oncology Nursing; 27: 300-308.

Graham JM, Liu YJ, Jeziorski JL. (2006). The Dyadic Adjustment Scale: A Reliability Generalization Meta-Analysis. Journal of Marriage and Family; 68: 701-717.

Gray RE, Fitch M, Phillips C, Labrecque M, Fergus K. (2000). To tell or not to tell: Patterns of disclosure among men with prostate cancer. Psycho-Oncology; 9: 273-282.

Gustavsson-Lilius M. (2010). Psychological consequences of cancer from the salutogenic and dyadic perspective. Helsinki: Helsinki University Print.

Harden J, Sanda MG, Wei JT, Yarandi HN, Hembroff L, Hardy J, Northouse L. (2013a). Survivorship After Prostate Cancer Treatment: Spouses' Quality of Life at 36 Months. Oncology Nursing Forum; 40: 567-573.

Harden J, Sanda M, Wei J, Yarandi H, Hembroff L, Hardy J, Northouse L, PROSTQA Consortium Study Group. (2013b). Partners' long-term appraisal of their caregiving experience, marital satisfaction, sexual satisfaction, and quality of life 2 years after prostate cancer treatment. Cancer Nursing; 36: 104-113.

Harden J, Schafenacker A, Northouse L, Mood D, Smith D, Pienta K, Hussain M, Baranowski K. (2002). Couples' experiences with prostate cancer: Focus group research. Oncology Nursing Forum; 29: 701-709. 
Harden J. (2005). Developmental life stage and couples' experiences with prostate cancer: A review of the literature. Cancer Nursing; 28: 85-98.

Harden JK, Northouse LL, Mood DW. (2006). Qualitative analysis of couples' experience with prostate cancer by age cohort. Cancer Nursing; 29: 367-377.

Hays R, Sherbourne C, Mazel R. (1993). The RAND 36-Item Health Survey 1.0. Health Economics; 2: 217-227.

Horner-Johnson W, Krahn G, Andresen E, Hall T, Rehabilitation Research and Training Center Expert Panel on Health Status Measurement. (2009). Developing summary scores of health-related quality of life for a population-based survey. Public Health Reports (Washington, D.C.: 1974); 124: 103-110.

Jenewein J, Zwahlen R, Zwahlen D, Drabe N, Moergeli H, Buchi S. (2008). Quality of life and dyadic adjustment in oral cancer patients and their female partners. European Journal of Cancer Care; 17: 127-135.

Kershaw TS, Mood DW, Newth G, Ronis DL, Sanda MG, Vaishampayan U, Northouse LL, (2008). Longitudinal Analysis of a Model to Predict Quality of Life in Prostate Cancer Patients and their Spouses. Annals of Behavioral Medicine; 36: 117-128.

Lafaye A, Petit S, Richaud P, Houédé N, Baguet F, Cousson-Gélie F. (2014). Dyadic effects of coping strategies on emotional state and quality of life in prostate cancer patients and their spouses. Psycho-oncology; 23: 797-803.

Lehto U, Helander S, Taari K, Aromaa A. (2015). Patient experiences at diagnosis and psychological well-being in prostate cancer: A Finnish national survey. European Journal of Oncology Nursing; 19: 220-229. 
Maliski SL, Heilemann MV, McCorkle R. (2002). From "death sentence" to "good cancer": Couples' transformation of a prostate cancer diagnosis. Nursing Research 51: 391-397.

Merz EL, Malcarne VL, Ko CM, Sadler M, Kwack L, Varni JW, Sadler GR. (2011). Dyadic concordance among prostate cancer patients and their partners and health-related quality of life: Does it matter? Psychology \& Health; 26: 651-666.

Munro BH. (2005). Statistical methods for health care research. Philadelphia: Lippincott Williams \& Wilkins.

Northouse LL, Mood DW, Montie JE, Sandler HM, Forman JD, Hussain M, Pienta KJ, Smith DC, Sanda MG, Kershaw T. (2007). Living with prostate cancer: Patients' and spouses' psychosocial status and quality of life. Journal of Clinical Oncology; 25: 4171-4177.

O'Shaughnessy PK, Ireland C, Pelentsov L, Thomas LA, Esterman AJ. (2013). Impaired sexual function and prostate cancer: a mixed method investigation into the experiences of men and their partners. Journal of Clinical Nursing; 22: 3492-3502.

O'Shaughnessy PK, Laws TA, Esterman AJ. (2015). The Prostate Cancer Journey: Results of an Online Survey of Men and Their Partners. Cancer Nursing; 38: E1-E12.

Osoba D, Bezjak A, Brundage M, Zee B, Tu D, Pater J, Quality of Life Committee of the NCIC CTG. (2005). Analysis and interpretation of health-related quality-of-life data from clinical trials: Basic approach of The National Cancer Institute of Canada Clinical Trials Group. European Journal of Cancer; 41: 280-287.

Paterson C, Robertson A, Smith A, Nabi G. (2015). Identifying the unmet supportive care needs of men living with and beyond prostate cancer: A systematic review. European Journal of Oncology Nursing; 19: 405-418. 
Pekkonen M. (2010). Terveyteen liittyvä elämänlaatu laitoskuntoutuksen vaikuttavuuden arvioinnissa: RAND-36-mittarin soveltuvuus työikäisten laitoskuntoutuksen ongelmaprofiilin määrittämiseen ja kuntoutuksen vaikutusten arvioimiseen (Abstract in English). Helsinki: Invalidisäätiö.

Regan TW, Lambert SD, Kelly B, McElduff P, Girgis A, Kayser K, Turner J. (2014). Crosssectional relationships between dyadic coping and anxiety, depression, and relationship satisfaction for patients with prostate cancer and their spouses. Patient Education \& Counseling; 96: 120-127.

Resendes LA, McCorkle R. (2006). Spousal Responses to Prostate Cancer: An Integrative Review. Cancer Investigation; 24: 192-198.

Saarijärvi S, Hyyppä MT, Lehtinen V, Alanen E. (1990). Chronic low back pain patients and spouse. Journal of Psychosomatic Research; 34: 117-122.

Saarijärvi S. (1991). Family-oriented rehabilitation of a patient with chronic low back pain. A controlled study of couple therapy in the rehabilitation of chronic low back pain patients. Turku: Publications of the Social Insurance Institution.

Sanda MG, Dunn RL, Michalski J, Sandler HM, Northouse L, Hembroff L, Lin X, Greenfield TK, Litwin MS, Saigal CS, Mahadevan A, Klein E, Kibel A, Pisters LL, Kuban D, Kaplan I, Wood D, Ciezki J, Shah N, Wei JT. (2008). Quality of life and satisfaction with outcome among prostate-cancer survivors. New England Journal of Medicine; 358: $1250-1261$.

Spanier G. (1976). Measuring dyadic adjustment: New scales for assessing the quality of marriage and similar dyads. Journal of Marriage and Family; 38: 15-28. 
Stenberg U, Ruland CM, Miaskowski C. (2010). Review of the literature on the effects of caring for a patient with cancer. Psycho-Oncology; 19: 1013-1025.

Treiyer A, Anheuser P, Butow Z, Steffens J. (2011). A single center prospective study: Prediction of postoperative general quality of life, potency and continence after radical retropubic prostatectomy. Journal of Urology; 185: 1681-1685.

Vasarainen H, Malmi H, Maattanen L, Ruutu M, Tammela T, Taari K, Rannikko A, Auvinen A. (2013). Effects of prostate cancer screening on health-related quality of life: results of the Finnish arm of the European randomized screening trial (ERSPC). Acta Oncologica; 52: $1615-1621$.

Ware JEJ, Sherbourne CD. (1992). The MOS 36-item short-form health survey (SF-36): I. conceptual framework and item selection. Medical Care; 30: 473-483.

Winters-Stone KM, Lyons KS, Nail LM, Beer TM. (2012). The Exercising Together project: Design and recruitment for a randomized, controlled trial to determine the benefits of partnered strength training for couples coping with prostate cancer. Contemporary Clinical Trials; 33: 342-350.

Ylilehto H. (2005). Postpartum depression - blocked joy. A salutogenic study of women's experiences during childbed. Oulu: Oulu University Press.

Zhan L. (1992). Quality of life: conceptual and measurement issues. Journal of Advanced Nursing; 17: 795-800. 
Table1. Demographic characteristics of patients with prostate cancer $(n=232)$ and their spouses $(n=229)$

\begin{tabular}{|c|c|c|c|c|}
\hline \multirow[b]{2}{*}{ Variable } & \multicolumn{2}{|c|}{$\begin{array}{c}\text { Patients with } \\
\text { prostate cancer }\end{array}$} & \multicolumn{2}{|c|}{ Spouses } \\
\hline & $\mathbf{n}$ & $\%$ & $\mathbf{n}$ & $\%$ \\
\hline \multicolumn{5}{|l|}{ Age years } \\
\hline$\leq 59$ & 42 & 18 & 60 & 26 \\
\hline $60-69$ & 98 & 42 & 104 & 46 \\
\hline$\geq 70$ & 92 & 40 & 65 & 28 \\
\hline \multicolumn{5}{|l|}{ Duration of marital relationship (years) } \\
\hline$\leq 25$ & 57 & 25 & & \\
\hline $26-40$ & 58 & 25 & & \\
\hline$\geq 41$ & 116 & 50 & & \\
\hline \multicolumn{5}{|l|}{ Basic education } \\
\hline Elementary school/civic school & 148 & 64 & 108 & 47 \\
\hline $\begin{array}{l}\text { Comprehensive school/lower } \\
\text { Secondary school }\end{array}$ & 49 & 21 & 61 & 27 \\
\hline Upper secondary school & 35 & 15 & 60 & 26 \\
\hline \multicolumn{5}{|l|}{ Vocational qualifications } \\
\hline Initial vocational qualification & 69 & 30 & 65 & 29 \\
\hline Further vocational qualification & 59 & 26 & 71 & 32 \\
\hline Polytechnic/university degree & 23 & 10 & 31 & 14 \\
\hline No vocational qualification & 76 & 34 & 55 & 25 \\
\hline \multicolumn{5}{|l|}{ Employment status } \\
\hline Working & 99 & 43 & 107 & 47 \\
\hline Not working & 133 & 57 & 122 & 53 \\
\hline \multicolumn{5}{|l|}{ Chronic diseases } \\
\hline Yes & 160 & 69 & 147 & 64 \\
\hline No & 72 & 31 & 82 & 36 \\
\hline \multicolumn{5}{|l|}{ Treatment method } \\
\hline Surgery & 62 & 27 & & \\
\hline Radiation therapy & 32 & 14 & & \\
\hline Hormonal treatment & 53 & 23 & & \\
\hline Non-invasive care & 80 & 36 & & \\
\hline
\end{tabular}


Table 2. Perceived marital relationship in prostate cancer patients $(n=232)$ and their spouses $(n=229)$ before the start of prostate cancer treatments

Patients Spouses

\begin{tabular}{|c|c|c|c|c|c|c|c|c|c|}
\hline & Mean (SD) & $\begin{array}{l}\text { Agree } \\
\mathrm{n}(\%)\end{array}$ & $\frac{\frac{\text { Sometimes }}{\text { disagree }}}{\mathrm{n}(\%)}$ & $\begin{array}{c}\text { Disagree } \\
\mathrm{n}(\%)\end{array}$ & Mean (SD) & $\begin{array}{l}\text { Agree } \\
n(\%)\end{array}$ & $\frac{\text { Sometimes }}{\frac{\text { disagree }}{\mathrm{n}(\%)}}$ & $\begin{array}{c}\text { Disagree } \\
\mathrm{n}(\%)\end{array}$ & p-value ${ }^{1}$ \\
\hline $\begin{array}{l}\text { Marital satisfaction total } \\
\text { score }\end{array}$ & $4.0(0.4)$ & & & & $4.0(0.5)$ & & & & 0.427 \\
\hline Dyadic consensus & $4.0(0.5)$ & & & & $4.1(0.6)$ & & & & 0.134 \\
\hline Handling family finances & & $190(82)$ & $35(15)$ & $6(3)$ & & $176(77)$ & $41(18)$ & $11(5)$ & \\
\hline Matters of recreation & & $178(77)$ & $49(21)$ & $4(2)$ & & $168(74)$ & $48(21)$ & $11(5)$ & \\
\hline Things believed important & & $191(83)$ & $38(17)$ & $1(0.4)$ & & $199(88)$ & $22(10)$ & $6(2)$ & \\
\hline Philosophy of life & & $185(80)$ & $44(19)$ & $2(1)$ & & $178(78)$ & $41(18)$ & $8(4)$ & \\
\hline Time spent together & & $181(78)$ & $44(19)$ & $6(3)$ & & $177(78)$ & $45(20)$ & $6(2)$ & \\
\hline Demonstrations of affection & & $157(68)$ & $67(29)$ & $7(3)$ & & $152(67)$ & $60(27)$ & $15(6)$ & \\
\hline Sexual relations & & $139(60)$ & $68(30)$ & $23(10)$ & & $144(64)$ & $63(28)$ & $19(8)$ & \\
\hline Friends & & $186(81)$ & $39(17)$ & $5(2)$ & & $182(80)$ & $33(15)$ & $12(5)$ & \\
\hline \multirow{2}{*}{$\begin{array}{l}\text { Ways of dealing with } \\
\text { relatives or in-laws }\end{array}$} & & $171(74)$ & $52(23)$ & $8(3)$ & & $163(72)$ & $54(24)$ & $10(4)$ & \\
\hline & & $\underline{\text { Often }}$ & $\underline{\text { Sometimes }}$ & $\underline{\text { Seldom }}$ & & $\underline{\text { Often }}$ & $\underline{\text { Sometimes }}$ & $\underline{\text { Seldom }}$ & \\
\hline $\begin{array}{l}\text { Dyadic cohesion } \\
\text { Calmly discuss something }\end{array}$ & $3.9(0.6)$ & & & & $4.0(0.7)$ & & & & 0.034 \\
\hline Calmly discuss something & & $192(83)$ & $30(13)$ & $9(4)$ & & $187(82)$ & $31(13)$ & $11(5)$ & \\
\hline Work together on a project & & $162(70)$ & $60(26)$ & $9(4)$ & & $164(72)$ & $46(20)$ & $18(8)$ & \\
\hline Exchange ideas & & $152(66)$ & $68(30)$ & $11(4)$ & & $153(67)$ & $62(27)$ & $14(6)$ & \\
\hline Dyadic s & $4.3(0.6)$ & & & & $4.1(0.7)$ & & & & 0.001 \\
\hline Considered divorce & & $1(0.4)$ & $12(5)$ & $217(94)$ & & $6(3)$ & $31(13)$ & $191(84)$ & \\
\hline Spousal quarrel & & $6(3)$ & $79(34)$ & $146(63)$ & & $9(4)$ & $84(37)$ & $136(59)$ & \\
\hline Communication & $3.7(0.5)$ & & & & $3.8(0.6)$ & & & & 0.160 \\
\hline $\begin{array}{l}\text { Fail to express disagreement } \\
\text { fears of anger }\end{array}$ & & $18(8)$ & $103(44)$ & $110(48)$ & & $21(9)$ & $70(31)$ & $138(60)$ & \\
\hline $\begin{array}{l}\text { Difficult to express true } \\
\text { feelings }\end{array}$ & & $5(2)$ & $57(25)$ & $169(73)$ & & $20(9)$ & $61(27)$ & $147(64)$ & \\
\hline $\begin{array}{l}\text { Hesitant to discuss certain } \\
\text { things because of fear of } \\
\text { hurt feelings }\end{array}$ & & $13(6)$ & $56(24)$ & $162(70)$ & & $9(4)$ & $60(26)$ & $159(70)$ & \\
\hline $\begin{array}{l}\text { Complain that you don't } \\
\text { understand }\end{array}$ & & $15(7)$ & $71(30)$ & $145(63)$ & & $11(5)$ & $47(21)$ & $169(74)$ & \\
\hline $\begin{array}{l}\text { Engage in outside interests } \\
\text { and activities together }\end{array}$ & & $54(23)$ & $112(49)$ & $65(28)$ & & $50(22)$ & $76(33)$ & $102(45)$ & \\
\hline Pretend listening & & $14(6)$ & $63(27)$ & $154(67)$ & & $6(2)$ & $45(20)$ & $177(78)$ & \\
\hline
\end{tabular}

${ }^{1}$ Wilcoxon Signed Ranks test

Significant $\mathrm{p}$ value in boldface $(\mathrm{p}<0.05)$. 
Marital relationship \& HRQoL

Table 3. Factors associated with health-related quality of life according to hierarchical logistic regression models with the enter method

\begin{tabular}{|c|c|c|c|c|c|c|c|c|c|c|c|c|c|c|c|c|}
\hline & \multicolumn{2}{|c|}{$\begin{array}{c}\text { Physical } \\
\text { functioning }\end{array}$} & \multicolumn{2}{|c|}{$\begin{array}{l}\text { Role functioning/ } \\
\text { physical }\end{array}$} & \multicolumn{2}{|c|}{$\begin{array}{c}\text { Role } \\
\text { functioning/ } \\
\text { emotional }\end{array}$} & \multicolumn{2}{|c|}{ Energy } & \multicolumn{2}{|c|}{$\begin{array}{l}\text { Emotional well- } \\
\text { being }\end{array}$} & \multicolumn{2}{|c|}{ Social functioning } & \multicolumn{2}{|c|}{ Bodily pain } & \multicolumn{2}{|c|}{ General health } \\
\hline & $\% *$ & $\mathrm{p}$-value & $\% *$ & $\mathrm{p}$-value & $\% *$ & p-value & $\% *$ & p-value & $\% *$ & p-value & $\% *$ & $\mathrm{p}$-value & $\% *$ & $\mathrm{p}$-value & $\% *$ & p-value \\
\hline $\begin{array}{l}\text { Marital } \\
\text { relationship }^{b}\end{array}$ & 9.1 & 0.148 & 5.1 & 0.760 & 4.7 & 0.469 & 12.6 & 0.022 & 15.9 & $<0.001$ & 10.5 & 0.147 & 5.6 & 0.925 & 16.5 & 0.004 \\
\hline $\begin{array}{l}\text { Spouses } \\
\text { Background } \\
\text { variables }^{c}\end{array}$ & 11.5 & $<0.001$ & 8.6 & 0.003 & 6.9 & 0.016 & 4.4 & 0.133 & 2.1 & 0.580 & 4.9 & 0.089 & 8.2 & 0.005 & 13.0 & $<0.001$ \\
\hline $\begin{array}{l}\text { Marital } \\
\text { relationship }^{\mathbf{b}}\end{array}$ & 12.2 & 0.797 & 10.1 & 0.473 & 11.2 & 0.035 & 8.0 & 0.076 & 13.5 & $<0.001$ & 9.9 & 0.018 & 10.5 & 0.245 & 14.8 & 0.363 \\
\hline
\end{tabular}

$* \mathbf{R}^{2}$ Cox \& Snell

Significant $p$-value for the $R^{2}$ bolded $(\mathbf{p}<0.05)$

a Age, Duration of marital relationship, Basic education, Vocational qualifications, Employment status, Chronic diseases, Treatment method

${ }^{b}$ Dyadic consensus, Dyadic cohesion, Dyadic satisfaction, Communication

${ }^{c}$ Age, Duration of marital relationship, Basic education, Vocational qualifications, Employment status, Chronic diseases 